\title{
AS INFLUÊNCIAS EXTERNAS NA DEFINIÇÃO DO TIME DO CORAÇÃO: ANALISANDO AS ESCOLHAS DOS ALUNOS DE UM COLÉGIO PÚBLICO ESTADUAL DA CIDADE DE PONTA GROSSA-PR
}

\author{
THE EXTERNAL INFLUENCES IN THE DEFINITION OF A TEAM TO BE \\ SUPPORTED ANALYZING THE STUDENTS' CHOICE OF A PUBLIC SCHOOL \\ IN THE CITY OF PONTA GROSSA - PR
}

\author{
Wendell Luiz Linhares ${ }^{*}$ \\ Miguel Archanjo de Freitas Jr. ${ }^{* *}$
}

\begin{abstract}
RESUMO
Esta investigação objetivou compreender os principais aspectos que interferem na construção do gosto pelo time de futebol. O estudo foi realizado com alunos do Ensino Médio de um Colégio Público Estadual, localizado no município de Ponta Grossa - Paraná. Para desenvolvê-lo utilizou-se um questionário estruturado composto por 16 questões, o qual foi aplicado numa população de 272 discentes com idade entre 15 e 17 anos e uma amostra de 239 participantes que retornaram o Termo de Consentimento Livre e Esclarecido (TCLE). Para análise dos resultados, utilizouse a abordagem quanti-qualitativa. Identificou-se que a "família", predomina no quesito escolha/definição do time que o indivíduo irá torcer. Verificou-se a existência de indivíduos que torcem por um time brasileiro e por outro estrangeiro. Percebeu-se que esta segunda opção não está diretamente relacionada a família, mas ao processo de globalização, que levou os indivíduos a usar outros veículos midiáticos, canais de comunicação e atividades de entretenimento, favorecendo cada vez mais a visibilidade e a aproximação de times e campeonatos europeus.
\end{abstract}

Palavras-chave: Identidade; Pertencimento; Família; Globalização.

\begin{abstract}
This investigation aims to understand the main aspects which interfere in the choice of a soccer team to support. The study involved the students of a public school in the county of Ponta Grossa in the state of Paraná. In order to develop this study it was used a questionnaire of 16 questions and it was applied to a group of 272 students at the age of 15 to 17 years old and a sample of 239 who gave back the free allowance term of participation, called in Portuguese (TCLE). To analyze the data it was used a quantity qualitative approach. It could be identified that "the family" is the predominant factor in the choice/definition of the team that he/she will support. It was identified the existence of some individuals who support a Brazilian team as well as a foreign one. It could be realized that in the second choice there is no relation with the family but with the globalization process itself which allowed to those individuals to use the media and channels of communication and others
\end{abstract}

\footnotetext{
"Mestre em Ciências Sociais Aplicadas pela Universidade Estadual de Ponta Grossa (UEPG), Docente do Instituto Educacional Arautos do Evangelho - Ponta Grossa,wendell.luiz@hotmail.com.

"Doutor em História pela Universidade Federal do Paraná (UFPR), Docente do Departamento de Educação Física e do Programa de Pós-Graduação em Ciências Sociais Aplicadas da Universidade Estadual de Ponta Grossa (UEPG), mfreitasjr@uepg.br.
} 
entertainment activities which make possible a visibility and approximation to the teams of the European Championships.

Key Words: Identity, Belonging, Family, Globalization.

\section{INTRODUÇÃO}

É inegável a elevada significância cultural e representatividade que o "fenômeno" futebol adquiriu no Brasil no decorrer do século passado. Apesar de caracterizar-se inicialmente como uma prática elitizada, a partir de meados da década de 1920, o futebol se popularizou de tal forma que passou a receber a alcunha de esporte nacional. (RIBEIRO, 2003; DAOLIO, 2006). Desta forma, passou a estar presente no cotidiano da população brasileira, mediante um sistema de criação, interpretação de símbolos e práticas associadas a outros elementos sociais e culturais. (GUEDES, 1982).

Freitas Júnior (2012) ao argumentar acerca da relevância do futebol, indica que ele é um símbolo significante para o sistema cultural mundial, e no Brasil, este esporte é, em certa medida, imposto como uma força capaz de penetrar a vida dos habitantes locais, influenciando na estruturação dos habitus, dos costumes, dos sentimentos, dos cotidianos e das identidades individuais e coletivas deles.

A relação entre futebol e identidade no Brasil pode ser visualizada a partir de diversos referentes, como o futebol de várzea, as relações de gênero no futebol, o futebol entre amigos, o futebol profissional, entre outros.

No que se refere ao futebol profissional, tal relação se dá mais especificamente pela esfera clubística ou pelo clube de futebol do "coração". Ressalta-se que no futebol, sobretudo por tal esporte estar permeando o cotidiano dos brasileiros, tornase comum verificar que muitos "palpites" sejam apresentados nos mais diferentes ambientes, inclusive no espaço acadêmico, muitas vezes sem ter realizado pesquisas que sustente o ponto de vista apresentado. Diante destes apontamentos emerge a seguinte questão investigativa: quais são os elementos que influenciam o indivíduo na escolha do clube de futebol para o qual ele irá torcer?
Assim, estabeleceu-se como objetivo do presente estudo, compreender como se dá a criação do gosto pelo time de futebol. Para isto, buscou-se compreender o processo de assimilação dos discentes matriculados no Ensino Médio de um Colégio Público Estadual, localizado na região central no município de Ponta Grossa - Paraná, no ano letivo de 2015. Justifica-se o presente estudo, pois, entende-se que ao compreender os motivos que influenciam e, por conseguinte, possibilitam o indivíduo a gostar de algo, permite-nos compreender uma parte significativa do comportamento humano, que neste estudo, utilizou-se o esporte como um fenômeno social para identificar este processo.

\section{MÉTODO}

Enquanto caracterização do estudo, entendese que o mesmo se pauta em Gil (2008), que define como um estudo de campo do tipo levantamento, no qual está direcionado pelo questionamento direto as pessoas, as quais o comportamento deseja-se saber. Por conseguinte, utilizou-se a técnica do tipo Survey. Para Babbie (2003) os Surveys podem ser utilizados para estabelecer enunciados descritivos sobre determinada população.

Desta forma, visando alcançar o objetivo proposto, optou-se, primeiramente, pelo fomento de um instrumento do tipo questionário, composto por 16 questões estruturadas, contendo 10 abertas e 6 fechadas. As questões utilizadas no instrumento, tratam sobre o time de preferência e os motivos que levaram o escolar a fazer tal escolha, faixa etária no momento da escolha e possíveis influencias, também questões que identificam o responsável pelo escolar na infância, nível de escolaridade, socioeconômico, clube de futebol de preferência e cidade de origem do mesmo, se o escolar já torceu por outro clube de futebol nacional e/ou europeu e qual jogador considera como o maior craque de futebol e se o professor de Educação Física exerceu ou não alguma influência para escolha do clube de futebol do "coração" do 
escolar. Entende-se que a partir das questões que tratam de diferentes aspectos, consiga-se identificar elementos significantes no que tange a escolha e o gosto clubístico.

Enquanto população e amostra, a pesquisa contou com uma população de 272 alunos com faixa etária de 15 a 17 anos, regularmente matriculados nos $1^{\text {os }}, 2^{\text {os }}$ e $3^{\text {os }}$ anos do ensino Médio do Colégio Público Estadual, entre fevereiro e abril de 2015. Optou-se por este colégio, pois a sua estrutura arquitetônica está localizada na região central da cidade de Ponta Grossa (PG), Estado do Paraná (PR). Por conseguinte, ele atende a uma população bastante heterogênea, com diferentes níveis sócio-econômicos e habitus culturais. Já a escolha dos escolares deveu-se ao fato de as suas aulas de Educação Física serem ministradas conjuntamente por uma professora concursada e dez (10) acadêmicos da Universidade Estadual de Ponta Grossa (UEPG), bolsistas do Programa Institucional de Bolsa de Iniciação à Docência (PIBID) ${ }^{1}$, fomentado pela Coordenação de Aperfeiçoamento de Pessoal de Nível Superior (CAPES).

A aplicação do instrumento ocorreu durante os horários das aulas de Educação Física. Os alunos foram orientados quanto ao preenchimento do questionário e aos objetivos científicos de tal aplicação. As participações foram arbitrárias, sendo confirmadas por intermédio da assinatura dos alunos, dos pais e/ou dos responsáveis, estes dois últimos agentes no que tange aos menores etários, do Termo de Consentimento Livre e Esclarecido para a pesquisa (TCLE). Desta forma, a pesquisa acabou com uma amostra objetivada em 239 escolares, sendo 122 meninos e 117 meninas.

Após aplicação do questionário, os mesmos foram recolhidos. Como técnica de análise, utilizou-se como embasamento metodológico um dos desígnios da Análise de Conteúdo (AC) Bardin (2016), neste sentido a organização e análise dos dados seguiu as seguintes fases: 1) Pré-Análise; 2) Exploração do Material; 3) Tratamento dos Resultados e 4) Análise dos dados e Inferência. Salienta-se que para o presente estudo, optou-se por analisar três questões: 1). Para

\footnotetext{
${ }^{1}$ PIBID - Programa Institucional de Bolsa de Iniciação à Docência é uma iniciativa para o aperfeiçoamento e a valorização da formação de professores para a educação básica, sendo fomentado pela Coordenação de Aperfeiçoamento de Pessoal de Nível Superior - CAPES, também é um projeto extensionista o qual propicia a iniciação ao ensino, o encontro com a comunidade e a pesquisa que é a reflexão dos acontecimentos daquela comunidade.
}

qual clube de futebol você torce?; 2). Por que você escolheu torcer por este clube de futebol?; 3). Você torce por algum clube de futebol fora do Brasil?. Justifica-se a delimitação por essas questões, pois elas coadunam com as objetivações desta pesquisa.

Desta forma, na Pré-Análise realizou-se uma primeira leitura das fontes, conhecida como leitura flutuante, a qual é o primeiro contato do pesquisador com o material coletado.

Na Exploração do Material, o mesmo foi sendo organizado e tabulado, sendo que os dados foram transferidos para uma planilha do tipo Microsoft office Professional 2016.

Para o Tratamento dos Resultados Obtidos, o qual constitui o momento que o resultado bruto passa a ser trabalhado afim que se tornem significativos, desta forma, fez-se o uso de operações estatísticas simples como de percentagens.

As Análises dos dados e Inferências se deram a partir da abordagem quantitativa e qualitativa. Do ponto de vista quantitativo, para Bardin (2016) quanto mais uma mensagem tiver uma frequência de aparição alta, mais ela é significativa para a população estudada. Do ponto de vista qualitativo, a autora indica que tal movimento é constituído de algumas características como sua validade voltada para a construções de deduções específicas sobre determinando acontecimento ou variável de inferências, pois, possui função de estabelecer categorias mais discriminantes.

Entende-se que embora os aspectos quantitativos e qualitativos apresentem aspectos distintos, ambos podem se complementar, tornando a análise dos dados mais rica.

\section{FUTEBOL E IDENTIDADE CLUBÍSTICA}

No Brasil, o futebol é considerado um fenômeno sociocultural. E como tal, possui aspectos que são salientados por Giglio (2007), como a capacidade deste esporte, em conjunto com outros elementos articulados, tem de identificar "seu" povo. Pois, não obstante, o esporte mencionado anteriormente, é percebido como um elemento da brasilidade e da construção da autoimagem do que é "ser brasileiro".

$\mathrm{Na}$ tentativa de compreender como o futebol se articula com a ideia de identidade, ou melhor, como a identidade desdobra-se, articulando-se com o futebol. Visitou-se a obra intitulada "Identidade" de 
Zigmund Bauman (2005). Nela, foi possível verificar o pensamento do sociólogo a partir da metáfora do quebra-cabeças.

De acordo com o autor, ideia de identidade pode ser entendida como um quebra-cabeças, o qual é formado por diversas peças, e, ao final, tem por objetivo formar e mostrar uma imagem. No caso do quebra-cabeças, do produto que pode ser encontrado na loja, essa imagem está dada. E pode ser verificada na própria caixa. Assim, é possível ter uma ideia do caminho que precisa ser percorrido para formação da imagem final.

Entretanto, embora a identidade siga a mesma perspectiva, sendo formada por diversas "peças", tal quebra-cabeça jamais estará completo, sempre faltará peças, e, não se saberá exatamente quantas. (BAUMAN, 2005). Não obstante, o autor alerta que não é possível começar pela imagem final, mas é necessário utilizar as peças já obtidas ou que pareçam valer a pena ter, para então, tentar agrupar ou reagrupalas no sentido de formar imagens agradáveis. Por conseguinte, ao pensar o Brasil, entende-se o futebol, como algo que é capaz de movimentar um grande contingente de pessoas, e, dessa forma, caracterizase como uma das peças ou facetas desse "quebracabeça", que contribui para a construção de uma possível identidade brasileira.

Assim, pode-se dizer que a identificação por parte dos brasileiros, com esse esporte, é sustentada por alguns pilares. Dentre esses pilares, destacam-se o Clube de Futebol e a Seleção Brasileira de Futebol. Sendo a primeira, ou seja, a identificação clubística, a principal forma de estruturação identitária com o esporte mencionado. Isso pode ser verificado, quando na porta da maternidade adereços do time de futebol da família são expostos (DAÓLIO, 1998), ou que, em diversos contextos, não se definiu o nome, nem a religião da criança, porém, o time de futebol já se sabe.

Por conseguinte, o futebol não pode ser feito como uma simples prática esportiva, órfã de significados e sentidos. Ele é muito mais complexo, pois, tem a capacidade de movimentar a nação no decorrer da vida. (GÍGLIO, 2007). De acordo com Damo (1998), no que se refere o pertencimento clubístico, o termo "nação" é utilizado para se referir ao total de pessoas que torcem para determinado clube de futebol. Desta forma, tem-se nos diferentes clubes, as "nações", os quais são conhecidos por torcedores e simpatizantes, como a "Nação Rubro Negra" do Flamengo, "Nação Tricolor" para o Grêmio e assim por diante.

O processo de construção de identidades, no que se refere ao clubismo, é algo complexo, como salienta Damo (2012), em que os clubes, de forma geral, são entidades que podem ser consideradas laicas. O autor ainda destaca que é possível identificar e relacionar um time com outras instituições tais como empresas, escolas, partidos políticos, causas, cidades e etc.. Entretanto, o mesmo faz uma ressalva, quanto aos chamados grandes clubes de futebol. Segundo o autor, estes "ousaram" transcender fronteiras, e, desta forma, fugiram das normas "estabelecidas", construindo assim, identidades próprias.

Pode-se entender o clubismo a partir de um sistema de representações, o qual é constituído por códigos os quais tem por função nortear e moldar o comportamento do indivíduo torcedor (DAMO, 2012). Com o sistema articulado de representações, o qual emerge a partir do clubismo, torna-se possível verificar elementos que ajudam a compor, em certa medida, como se constroem as rivalidades entre os clubes. Nesse sentido, de acordo com Damo:

Se observarmos as identidades e as diferenças que constituem as rivalidades no clubismo, veremos o quanto elas estão impregnadas por elementos pinçados do espectro mais amplo da sociedade, tensões que são drenadas para as arquibancadas dos estádios, tornando os eventos futebolísticos um espetáculo que extrapola a dimensão esportiva. A ideia de que certos enfrentamentos dramatizam os dilemas sociais é amplamente compartilhada por todos aqueles que se debruçam sobre o tema no campo das ciências sociais. (DAMO, 2012, p. 56).

O fato de que alguns clubes de futebol conseguirem transcender o território local, alcançando outras regiões, e serem reconhecidos como "grandes do futebol brasileiro" 2 , permite-nos pensar que tais clubes alcançaram esse status, devido ao acúmulo

\footnotetext{
${ }^{2}$ Os clubes de futebol que compõem o grupo seleto chamado de "grandes" é formado por quatro Estados. Estado de Minas Gerais: Clube Atlético Mineiro e Cruzeiro Esporte Clube; Estado do Rio Grande do Sul: Grêmio Foot-Ball Porto Alegrense e Sport Club Internacional; Estado do Rio de Janeiro: Botafogo de Futebol e Regatas, Clube de Regatas Flamengo, Clube de Regatas Vasco da Gama e Fluminense Futebol Clube; Estado de São Paulo: Santos Futebol Clube, São Paulo Futebol Clube, Sociedade Esportiva Palmeiras e Sport Club Corinthians Paulista.
} 
de capital simbólico que adquiriram no decorrer do tempo.

Esse grande volume de capital simbólico ${ }^{3}$ de acordo com Mosko (2007), pode ser visualizado através de algumas características como, a participação nos principais campeonatos nacionais e internacionais de futebol, conquistas de campeonatos nacionais e/ ou internacionais, tamanho da torcida e a mesma também se encontrar em outras regiões, patrimônio, maior visibilidade midiática, localização em grandes cidades/capitais e maior capacidade de investimento ${ }^{4}$. Não obstante, clubes que se encontram no interior dos Estados Federativos, ou Regiões Metropolitanas, apresentam um menor capital simbólico, enfrentando assim, uma difícil concorrência.

\section{A GLOBALIZAÇÃO DO FUTEBOL}

Pode-se pensar a globalização como “[...] uma manifestação contemporânea de duas "leis imanentes do capitalismo": a tendência a romper os limites à livre circulação do capital e a propensão do capital a transpor suas fronteiras políticas e conquistar novos circuitos de valorização.”. (PRONI, 1998, p.108). Logo, a globalização parece estar enraizada numa lógica mercantilista de consumo e capitalista.

Com o advento do fenômeno anteriormente citado, o futebol foi um esporte que ganhou grande destaque e proporção mundial (RIAL, 2008). Por conseguinte, observa-se que alguns dos reflexos oriundos dessa complexa relação, entre futebol e globalização foi a transformação desse fenômeno social em um produto cultural, social, político, financeiro (RIBEIRO, 2007), construtor de "novas" identidades, o qual ocupa um lugar de destaque midiático que foi adquirido no decorrer dos anos (VELOZO e DAÓLIO, 2017). Assim, o futebol também passou a seguir uma lógica mercantilista de consumo, sobretudo o futebol europeu com o surgimento da tendência do "futebolempresa" (BARBOSA, 2007).

\footnotetext{
${ }^{3} \mathrm{O}$ capital simbólico está relacionado a um certo prestígio, reconhecimento que pode ser conferido a determinado agente.

${ }^{4}$ Os aspectos citados, dentre outros, podem influenciar no momento da negociação relacionado ao direito de transmissão, bem como patrocinador principal e esportivo, nesse sentido, quanto maior volume de capital simbólico um clube de futebol adquire, maior possibilidade de aumentar seu volume de capital econômico e esse retroalimentar o capital simbólico, criando uma espécie de ciclo "virtuoso".
}

No futebol europeu, um dos primeiros reflexos da globalização no futebol deu-se na segunda metade da década de 70, na Itália, em que a televisão passa a transmitir partidas selecionadas, uma vez por semana e os clubes passam a receber uma quota por transmissão. (PRONI; ZAIA, 2007). Posteriormente, em 1981, houve a liberação para logomarca nos uniformes dos times, e na época a Juventus de Turim da Itália, obteve cerca de US\$ 800 mil por ano, o maior patrocínio da época, Milan da Itália e Bayern de Munique da Alemanha, acertaram por cerca de US\$ 400 mil por ano (PRONI; ZAIA, 2007). Nesse período, a crise na qual o Brasil atravessava, também atingiu os clubes de futebol. E, com objetivo de conter a crise que batia na porta dos clubes brasileiros, outras fontes de renda começaram a aparecer, como a venda de jogadores para a Europa, contratos assinados pelos clubes com a televisão entre outros. (HELAL; GORDON, 2002).

Na década de 90, mudanças no âmbito esportivo como o Decreto n. 981/93 o qual ficou conhecido como a "Lei Zico" e posteriormente transformado em lei federal n. 8.672/935 , tinha em seu corpo, elementos que contribuíam para o fomento do esporte no país. Enquanto isso na Europa, emerge discussões a respeito da situação dos jogadores profissionais. Isso pode ser verificado através do "Caso Bosman", que com a decisão da época foi considerada precedente de cunho revolucionário. (PRONI, 1998). Sendo seus reflexos no mercado europeu sentidos até hoje, possibilitando assim, uma maior flexibilização na relação entre o clube e o jogador.

Em 25 de março de 1998, foi aprovada pelo então Presidente da República Fernando Henrique Cardoso, a Lei n. 9.615/98 que ficou conhecida como "Lei Pelé "”. CEmbora não se tenha alcançado mudanças profundas como se pretendia, "as maiores mudanças ficaram no âmbito do futebol profissional, em que se previa o fim da Lei do Passe $^{8}$, a profissionalização dos clubes, a

\footnotetext{
${ }^{5}$ Ver: http://www.planalto.gov.br/ccivil_03/leis/L8672impressao.htm.

${ }^{6} \mathrm{O}$ Caso Bosman: Bosman era um jogador belga atuava em um clube da segunda divisão do seu país em 1988, entretanto em 1990, teve um grande corte em seu salário, também o mesmo foi impedido de se transferir para um clube Francês, assim entrou na justiça comum para tentar a liberação e tentar jogar. No ano de 1995, a UEFA perde a causa, o que provoca inúmeras e significativas transformações no futebol.

${ }^{7}$ Ver: http://www.planalto.gov.br/ccivil_03/leis/L9615Compilada.htm.

${ }^{8 \mathrm{~A}}$ Lei do Passe: A Lei do Passe $\mathrm{n}^{\circ} 6.354 / 76$, a qual foi elaborada no sentido do Estado (Regime Militar), buscava centralizar o poder. Neste sentido, a Lei do Passe mantinha o jogador de futebol preso ao clube, sendo assim o mesmo não tinha o direito de escolher qual agremiação defender.
} 
autonomia das empresas e a fiscalização do Ministério Público". (MEZZADRI, 2007, p.124). Porém, como indica o próprio autor, os maiores beneficiados foram os jogadores de futebol (MEZZADRI, 2007), pois, com o advento da "Lei Pelé", passaram a ter uma maior autonomia em suas carreiras, escolhendo o clube qual desejavam defender. Alguns estudiosos mostram que:

Os fatores que impulsionaram a saída de jogadores brasileiros para o futebol estrangeiro são: (i) os elevados salários pagos pelos clubes estrangeiros (cerca de cinco vezes mais que os clubes brasileiros); (ii) melhores condições de trabalho; (iii) a Lei Pelé (o fim do passe, a liberação/flexibilização do sistema de transferências de jogadores); (iv) o caso Bosman , que introduziu a liberdade de contrato e decretou o fim do sistema de cotas de jogadores estrangeiros nos países da Comunidade Europeia. (RODRIGUES, 2007, p. 69).

Vale ressaltar que tanto o "Caso Bosman", quanto a "Lei Pelé" ocasionaram uma mudança na estrutura e dinâmica do futebol mundial, demonstrando algumas implicações da globalização neste esporte. Abrindo fronteiras, tanto no campo político quanto no campo geográfico. Desta forma, o futebol foi gradativamente passando a constituir-se como um produto a ser consumido pelos torcedores, agora não somente a nível local, mas também, a nível global, pois, no caso brasileiro, os jogadores, aqueles que são as principais figuras para que o espetáculo possa ser construído e consumido, tem deixado cada vez mais cedo os palcos brasileiros, muito em função de todo processo apontado anteriormente, bem como, a grande disparidade econômica entre clubes brasileiros e europeus. Sendo a exportação dos jogadores a principal fonte de divisas do futebol latino americano. (RIBEIRO, 2007).

Esse processo de exportação implica na situação em que os torcedores brasileiros tem cada vez menos a oportunidade de acompanhar os jogadores destaques em seus times do "coração" e encontram na mídia, sobretudo na televisão aberta, fechada e internet um meio para acompanhar seus jogadores preferidos.

Observa-se então, um processo em que o mercado dita "novos caminhos" os quais perspectivam a construção de vínculos não duradouros, por partes dos jogadores, pois, os mesmos passaram a percorrer diversos países e por consequência, diversos clubes de futebol. (KOCH; FORELL, 2016). Ainda, segundo os autores, o futebol passa a configurar um campo híbrido em que estruturas e práticas que existiam em um dado momento, passam, a partir de combinações, a gerar outras estruturas e práticas. Esta perspectiva se dá no futebol a partir da abertura da zona de comércio de atletas, as quais permitem a naturalização dos mesmos para que defendam cores de outra nação.

Exemplos clubísticos, os quais são resultados de todos processo de combinação de estruturas e práticas, podem ser visualizados a partir de clubes de futebol como Real Madrid, Barcelona, Manchester United, Bayern de Munique, Juventus, Paris Saint Germain entre outros. De acordo com Fonseca (2016) tais clubes se tornaram globais e em torno deles passaram a girar contratações dos principais jogadores ou promessas do futebol mundial. Não obstante, são clubes que possuem o perfil desejado para que empresas associem suas marcas e, desta forma, consigam maiores cotas de patrocínio e televisão. Ainda de acordo com o autor:

Toda essa atividade comercial, a comercialização dos direitos de transmissão das partidas, os espaços nas camisas destinados aos patrocinadores, a utilização de determinada marca de material esportivo, a venda de um sem número de mercadorias com as cores dos times (flâmulas, bandeiras, roupas de bebê, canetas, camisas, bolas, tênis e ingressos para os jogos) tornou o futebol um negócio altamente lucrativo e globalizado. Os jogadores, vindos de todas as partes do globo tornaram-se as novas mercadorias de exportação de países pobres e em desenvolvimento. Resta, ao torcedor, a esperança de ver o craque nascido e criado dentro do seu clube disputando uma ou duas partidas em sua terra natal, ou sendo convocado pela seleção do seu país; ou, quando muito, depois de passar longas temporadas atuando no futebol europeu ele retorne para o encerramento de sua carreira no seu clube, quando sua capacidade como atleta já estará bastante reduzida. (FONSECA, 2016, p. 193).

Autores como Barrinha e Nunes (2004) apontam para a existência de um grupo seleto formado por jogadores, clubes de futebol e seleção, os quais fazem parte da cultura global. Os sujeitos que constitui o grupo aparecem frequentemente na televisão em um nível mundial, possuem maior capacidade de participar de campanhas publicitárias e, não obstante, criaram uma linguagem na qual possibilita pessoas 
de diferentes culturas adorar os mesmos jogadores tendo-os como ídolos.

Por conseguinte, os meios de comunicação como a Tv aberta e fechada - principalmente com o fenômeno do "Sky Gato", a internet em suas diversas formas de manifestações como os sites esportivos, as redes sociais, conteúdos e jogos via streaming, possibilitam um encurtamento da distância entre o torcedor e o jogador/clube de futebol europeu. Desta forma, entende-se que na globalização, os meios de comunicação são podem ser fonte de produção de identidades.

Koch e Forell (2016) indica que ao pensar a contemporaneidade, a construção de laços com o clube de futebol pode ocorrer a partir da força midiática. Os autores apontam que para o clube de futebol no exterior, a figura do jogador como um elemento que pode ser central nesta decisão. A relação que se estabelece entre o jogador e o torcedor não se pauta na significância do mesmo enquanto um ídolo de determinado clube local, mas sim, enquanto uma estrela global. (BARRINHA; NUNES, 2004). Ainda de acordo com os autores:

O futebolista de primeira linha está hoje em dia para um clube como um grande actor está para um filme. Contratar uma nova estrela permite obter resultados ainda antes de ela jogar, vendendo milhares de camisolas com o seu nome logo no dia em que é contratada. Beckham, por exemplo, esgotou as oito mil com o seu número que estavam disponíveis na loja do Real Madrid no dia em que assinou contrato, ainda antes de dar um pontapé na bola; ao longo da época vendeu-se um milhão de camisolas com o seu nome. Se um clube é uma marca reconhecida em todo o mundo, os jogadores são activos fundamentais. (BARRINHA; NUNES, 2004, p. 135).

A globalização tem impactado no futebol em diferentes áreas, como na econômica, na política, na geográfica e, por conseguinte, nas identidades em torno de tal esporte, sendo esta última, composta por uma característica fluída ou "liquida" (BAUMAN, 2005). A liquidez nos apresenta uma nova forma de enxergar a construção dos processos identitários, contrapondo assim, o modelo "fixo" que era pensado em décadas anteriores.
Por intermédio do questionário estruturado, foram analisadas as seguintes indagações: 1). Para qual clube de futebol você torce?; 2). Por que você escolheu torcer por este clube de futebol?; 3). Você torce por algum clube de futebol de fora do Brasil?

Ao analisar as respostas da questão "1", verificou-se que dos 239 respondentes, 73 indicaram torcer pelo Corinthians (30,54\%) - time localizado na Região Sudeste; 52 apontaram torcer pelo Flamengo $(21,76 \%)$ - time localizado na Região Sudeste; 35 assinalaram torcer pelo São Paulo (14,64\%) - time localizado na Região Sudeste; 19 indicaram torcer pelo Palmeiras (7,95\%) - time localizado na Região Sudeste; 19 apontaram torcer pelo Santos (7,95\%) time localizado na Região Sudeste; 08 assinalaram torcer pelo Operário Ferroviário Esporte Clube (3,35\%) - time localizado na Região Sul; 03 indicaram torcer pelo Grêmio (1,25\%) - localizado na Região Sul; 03 Assinalaram torcer pelo Internacional (1,25\%) - time localizado na Região Sul; 02 mencionaram torcer pelo Atlético Paranaense $(0,84 \%)$ - time localizado na Região Sul; 01 indicou torcer pelo Atlético Mineiro (0,42\%) - time localizado na Região Sudeste; 01 apontou torcer pelo Coritiba $(0,42 \%)$ time localizado na Região Sul; 01 assinalou torcer pelo Cruzeiro $(0,42 \%)$ - time localizado na Região Sudeste; 01 mencionou torcer pelo Vasco $(0,42 \%)$ time localizado na Região Sudeste; 17 apontaram não torcer para nenhum time $(7,11 \%)$ e 04 não informaram o time que torcem $(1,68 \%)$.

Através dos dados mencionados anteriormente, observou-se que $218(91,21 \%)$ indicaram torcer por algum time de futebol, entretanto, 21 (8,79\%) não torcem ou não informaram. Esses dados nos mostram que para o grupo estudado, o futebol se constitui num elemento com significativo e representativo, e pensando a identidade a partir da metáfora do quebracabeças, citada anteriormente por Bauman (2005), entende-se que o futebol é uma "peça" - parte - que integra e contribui na construção de uma identidade dos indivíduos - grande parte - que foram estudados.

\section{RESULTADOS E DISCUSSÃO}




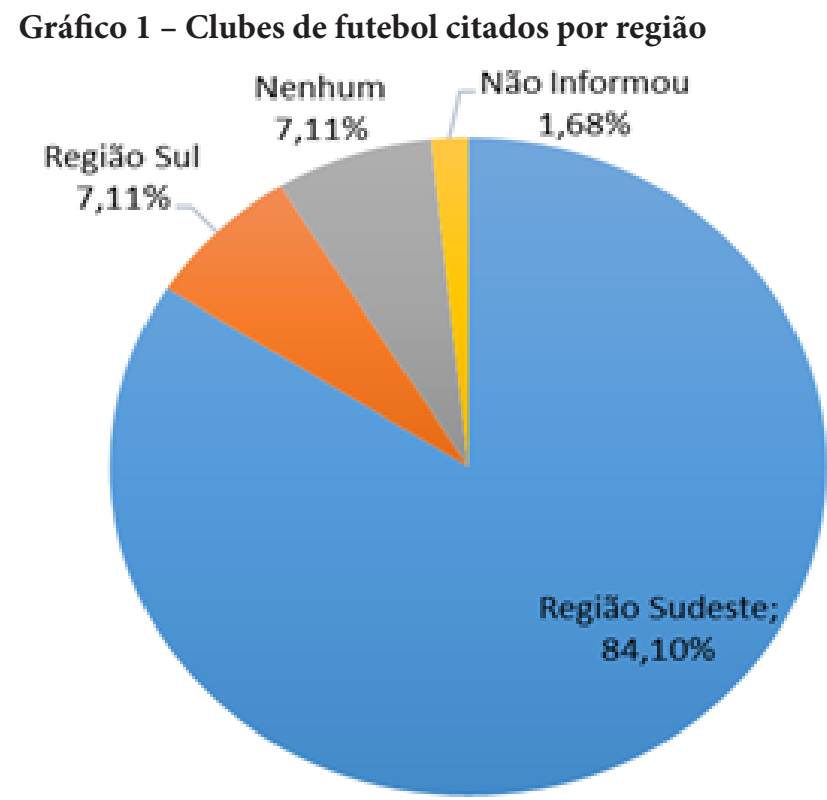

Fonte: Os autores

Ao observar a região de origem dos clubes de futebol indicados pelos escolares, verificou-se uma maior frequência de aparições sobretudo da região sudeste 84,10\% (201). Dos 13 times citados oito (08) estão localizados na região supracitada.

Não obstante, em um estudo realizado pela empresa BDO RCS (2017) que apresenta indicadores referentes aos valores das marcas dos clubes brasileiro de futebol, no período de 2012-2016, observou-se que das dez (10) marcas mais valiosas, 08 (oito) estão na região sudeste e 02 (dois) na região sul. Por conseguinte, tais marcas se tornam valiosas na medida que uma série de fatores como, a evolução dos valores recebidos pelos direitos de transmissão, ampliação das receitas de cada entidade (através do marketing, estádios, sócios e mídias), evolução do programa de sócio torcedor, aumentos dos valores recebidos de patrocinadores e empresas que querem associar sua marca ao clube, maior participação dos torcedor no negócio gerados pelas entidades, novas arenas com potencial amplo de exploração se articulam.

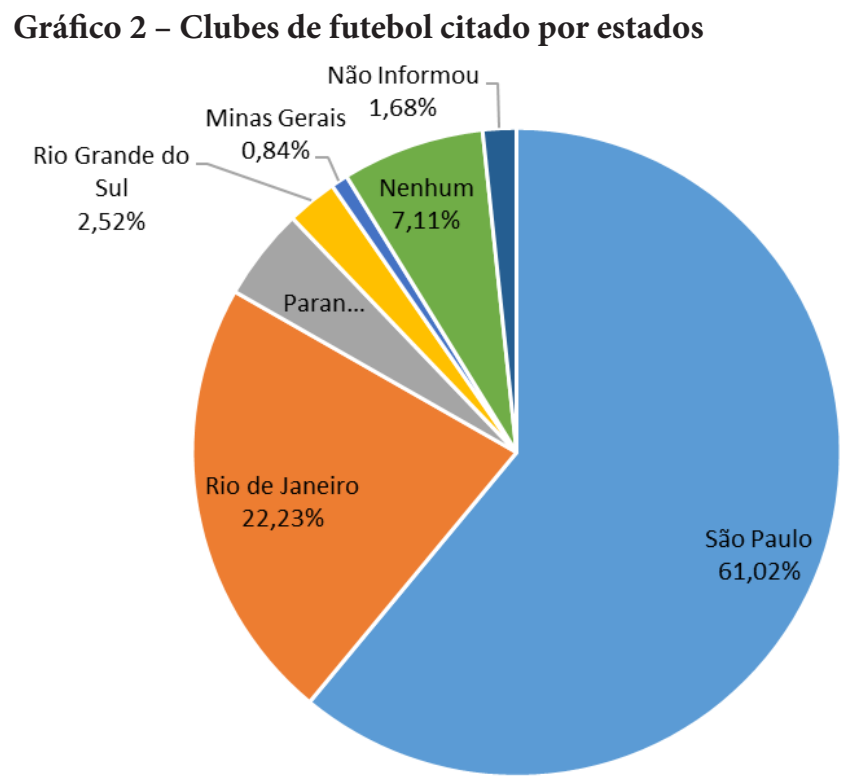

Fonte: Os autores

Ao observar o gráfico 2, identificou-se uma predominância de times dos estados de São Paulo (principalmente) e Rio de Janeiro. Ressalta-se que os times mencionados que se encontram localizados nos estados supramencionados, constituem o seleto e simbólico grupo dos "grandes" do futebol brasileiro". Por conseguinte, considerando que cada clube de futebol possui uma especificidade, é possível mapear alguns elementos como o poder econômico (maiores patrocínios e cotas de televisão), o histórico de grandes conquistas a nível nacional e internacional, uma torcida que transcende para outras regiões do Brasil, um maior número de aparições/cobertura midiática, entre outras, que quando combinados exerce uma função de distinção dentre outros clubes. Nesse sentido, Vasconcelos (2012), entende que esses times possuem os principais capitais que uma entidade futebolística pode ter, sendo eles, o capital político, o capital econômico, o capital social, o capital simbólico e o capital midiático. Que de certa forma, contribui para que outras regiões se configurem como uma espécie de periferia do futebol.

Dessa forma, quando se observa percentuais sobre o Estado do Paraná, torna-se possível enquadrálo como uma área periférica do futebol nacional. Isso se dá, por uma série de motivos, alguns deles já supramencionados, porém, ressalta-se a conformação histórica e cultural do estado. 
Nesse sentido, Da Silva (2011) corrobora ao indicar que o Paraná é um estado que possui características específicas, configurando-se um local multifacetado, quando considerado aspectos históricos e culturais. Pois, ainda segundo o autor, o estado mencionado passou por um processo formação tardio o que impactou na construção de sua identidade regional, influenciando no aspecto futebolístico. Migrantes de diversas regiões do país ocuparam locais vazios, estabeleceram outros hábitos que, não obstante, ocasionaram impacto em diversas esferas (política, econômica e cultural).

Ainda, Da Silva (2011) salienta que as ligações que no decorrer do tempo foram se estabelecendo com o estado de São Paulo e o Rio Grande do Sul, contribuíram para o surgimento de diferentes configurações, as quais, em certa medida, influenciam o indivíduo na escolha do clube de futebol para torcer.

Outro elemento que não pode ser ignorado na análise, são os diferentes veículos midiáticos (Rádio, Televisão, Jornal Impresso e a Internet). De acordo com Vasconcelos (2012), os veículos midiáticos aproximam os torcedores de informações de times dos mais variados cantos do Brasil, sobretudo os localizados nos grandes centros, deixando-os próximos da realidade cotidiana, inclusive do que até a provável equipe da própria cidade.

No Paraná, somente no início da década de 2000 iniciou-se um processo de regionalização da programação, sobretudo parte esportiva, com transmissões de partidas do Campeonato Paranaense e parte dos programas esportivos foram dedicados a informar notícias esportivas da região. No decorrer do tempo, mudanças foram feitas, e em 2018, observase uma programação esportiva voltada para notícias do esporte/futebol paranaense. Entretanto, vale destacar que quando se trata da disputa dos principais campeonatos nacionais (Copa do Brasil e Campeonato Brasileiro) e internacionais (Copa Libertadores e Copa Sulamericana), a preferência das transmissões ainda fica objetivada para os clubes do eixo Rio-São Paulo.
Gráfico - 3 Por que você escolheu torcer por este clube de futebol?

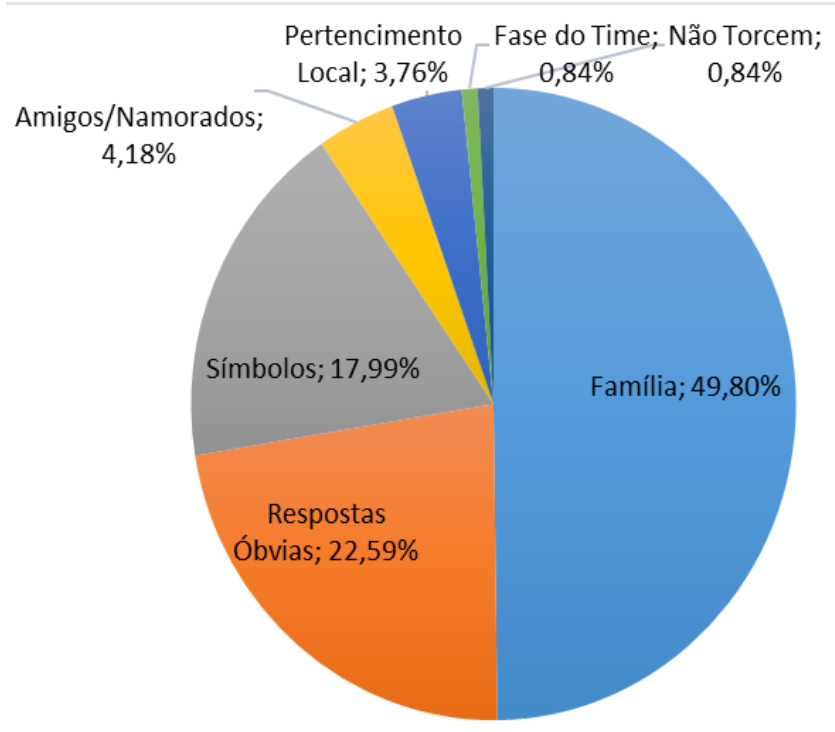

Fonte: Os autores

Após realizar aproximações e categorizar as respostas, observou-se que dos escolares estudados, $119(49,80 \%)$ indicaram a "Família" como o fator que influenciou sua escolha do clube de futebol para torcer. Nessa categoria, destaca-se a figura do "Pai" como principal elemento influenciador no momento da definição, pois a mesma, emergiu através de 86 $(35,98 \%)$ indicações dos escolares.

Os dados supracitados, demonstram dois aspectos que perpassam a construção de um desdobramento identitário, o qual seja, o clubístico. Tais aspectos, são apontados por Magalhães (2004), sendo eles, o pessoal, e o social. (MAGALHÃES, 2004). São distintos um do outro, porém, em certa maneira se articulam e se entrelaçam, ou seja, mesmo apresentando uma característica de distinção, demonstram ser interdependentes. Ainda, segundo Magalhães (2004), o processo de identificação, sempre tem uma ligação com aquilo que o indivíduo tem em comum, em relação a outros indivíduos. Entretanto, não se pode esquecer da outra face da moeda, ou

\footnotetext{
${ }^{9}$ Constituem a categoria "Família" respostas como: Influência da Família (0,42\%); Influência do Pai (35,98\%); Influência dos Pais (1,68\%); Influência do Irmão (2,92\%); Influência da Irmã (0,84\%); Influência do Tio (2,50\%); Influência da Tia (0,42\%); Influência do Avô (1,25\%); Influência da Mãe $(0,84 \%)$; Influência do Primo $(0,84 \%)$; Para Contrariar a Família (1,68\%); Pela tradição Familiar (0,42\%).
} 
seja, aquilo que o mesmo tem de diferente quando comparado ao outro.

Esse movimento, entre aquilo que se tem em comum a um e de diferente ao outro, possibilita estabelecer relações sociais e, por conseguinte, o indivíduo realiza a ação socializadora. Essa por sua vez, pode ser entendida por processos os quais Berger e Luckmann (1985) denominaram de "socialização primária" e "socialização secundária". Segundo os autores, a socialização primária tem por premissa, o indivíduo, ao nascer, tem o contato e recebe determinadas crenças, valores e visão de mundo de determinado grupo. Isso pode ser observado, sobretudo, na infância, em que o indivíduo tem na família, o suporte das primeiras relações e primeiras experiências. Sendo assim, mesmo a escolha do clube de futebol do coração ter um caráter pessoal, os dados demonstraram que ela também pode ser social, carregadas de valores, sentidos, significados e crenças. Já, a socialização secundária, é aquela em que os indivíduos estabelecem contatos com outros círculos, além da família. Neste momento, as relações que se iniciam e se estabelecem, normalmente estão pautadas através de outras locais ou instituições sociais como a escola, o trabalho, a igreja, a padaria, a sorveteria, clubes sociais e etc.. Nesse sentido, identificou-se A categoria "Amigo/Namorado" $" 10$ que cerca de $10(4,18 \%)$ escolares, apontaram ter sofrido influência de amigos ou namorado, ou seja, foram influenciados por indivíduos que se enquadram na socialização secundária.

Segundo Magalhães (2004), os valores que são internalizados na socialização primária têm como elemento de ligação a predominância da emoção, já, na socialização secundária, o elemento de ligação é o racional. Dessa forma, a autora salienta que na primeira os valores, as crenças e os comportamentos são internalizados contribuindo na construção da identidade do indivíduo, assim, tornam-se menos passíveis de sofrerem modificação, diferentemente daquilo que se aprende na socialização secundária.

Outra categoria que emergiu com 43 (17,99\%) indicações dos escolares, foi a de "Símbolos"". Essa

\footnotetext{
${ }^{10}$ Constituem a categoria "Amigo/Namorado", as seguintes respostas: Influência dos amigos (2,92\%); Influência do Namorado (1,26\%).

${ }^{11}$ Constituem a categoria "Símbolos", as seguintes respostas: Porque o clube de futebol é bom (9,62\%); Pela história do clube (0,84\%); Pela camisa do clube do coração (0,42\%); Pela identificação com o clube de futebol (3,34\%); Pela
}

categoria foi construída a partir de respostas que remetem a elementos/características específicas dos clubes. Ou seja, apresentam e/ou reforçam uma espécie de identificação muito próxima entre torcedor e clube de futebol. Em outras palavras, apresentam como elemento de mediação visual entre os torcedores e os clubes, bem como, torcedores e torcedores. (DAMO, 2012).

Identificou-se, também uma categoria relativa ao "Pertencimento Local"12 com 9 (3,76\%). Nesse aspecto, observa-se que, a escolha do clube de futebol para torcer, pode estar imbricado a aspectos étnicos, regionais e até raciais, e, estes reforçam determinados valores (DAMO, 1999), contribuem e/ou reforçam a construção/afirmação de determinada identidade.

Ainda, observou-se outra categoria relacionada com a "Fase" 13 em que o clube de futebol se encontrava no momento da definição do escolar. Nesse sentido, houveram $2(0,84 \%)$ indicações. Assim, pode-se inferir que a fase (sendo ela boa) contribui para um aumento do volume de capital simbólico do clube de futebol em questão, a "Boa Fase", está relacionada as vitórias, as conquistas de títulos.

Com 54 (22,59\%) de indicações dos escolares, encontrou-se a categoria "Respostas curtas e obvias"14 e $2(0,84 \%)$ dos escolares informaram que "não torcem" por clube de futebol algum.

torcida (1,25\%); Pela tradição do clube de futebol (0,42\%); Porque considero que os melhores jogadores estão no clube de futebol ( $0,42 \%)$; Porque gostou das cores do clube de futebol (1,25\%); Porque sempre gostou do estilo de jogo do clube de futebol $(0,42 \%)$.

${ }^{12}$ Constituem a categoria "Pertencimento Local", as seguintes respostas: Porque representa minha cidade (2,92\%); Porque é da cidade natal $(0,42 \%)$; Porque prefere clubes de futebol do estado (Paraná);

${ }^{13}$ Constituem a categoria "Fase" as seguintes respostas: Porque o clube de futebol passava por uma boa fase $(0,42 \%)$; Porque quando pequeno o clube de futebol só ganhava $(0,42 \%)$.

${ }^{14}$ Constituem a categoria "Respostas curtas e óbvias", as seguintes respostas: Não Sabe (0,42\%); Não tem explicações (10,46\%); De tanto encherem minha cabeça $(0,42 \%)$; Para ter um time para torcer $(0,42 \%)$; Porque sim $(0,84 \%)$ Torce desde pequeno (0,42\%); Emocionou o coração (0,42\%); Ama o time $(0,42 \%)$; Gosta do time (5,02\%);\%); Influência na Infância (0,42\%); Escolha própria (1,68\%); Por ter assistidos alguns jogos $(1,68 \%)$ 


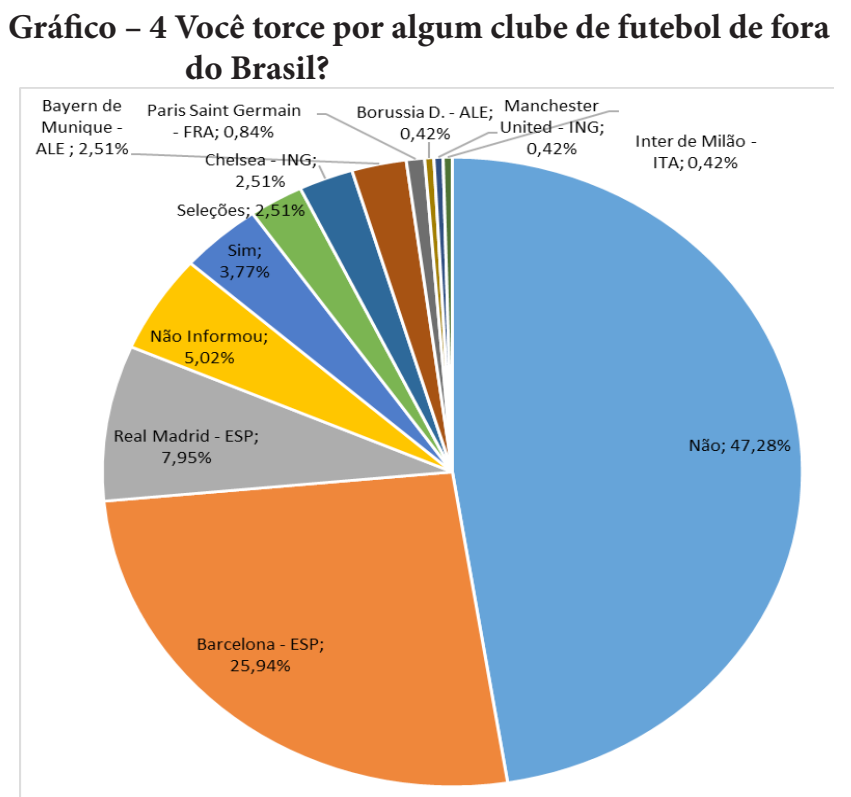

Fonte: Os autores

Observa-se no gráfico 4 que 114 (47,70\%) dos escolares indicaram torcer por equipes de futebol do exterior. Nesse sentido, é possível verificar o processo e mudanças estruturais, devido a mundialização de padrões de origem tecnológicas e culturais em escala mundial. (RIBEIRO, 2007). Não obstante, infere-se a possibilidade de uma forma diferente no que se refere a identificação do entre o indivíduo e o time, que pode ser denominada de bifiliação, a qual se dá a partir da escolha por dois clubes de futebol para torcer.

Visualiza-se que essa possibilidade de identificação e por consequência de pertencimento clubístico, que ocorre a partir da vinculação por um clube nacional e um clube internacional, pode ser pensada como possíveis efeitos da relação entre futebol e globalização. Dessa forma, verifica-se que com o a troca entre processo identitários locais para processos identitários globais, torna o futebol um fenômeno esportivo cada vez mais global.

A globalização tem por princípio, a desterritorialização de símbolos e significados, os quais pertencem a determinado grupo social e tornálos passíveis de identificação e não-estranhamento a outros contextos. (BARBOSA, 2007). O autor ainda apresenta a ideia de que através da globalização, é possível criar um território cultural para que os símbolos sejam consumidos. (BARBOSA, 2007).
No que se trata do futebol, hoje mais do que nunca, é possível consumi-lo por várias formas. Seja por meio dos produtos como as vestimentas, suvenires ou o consumo do jogo in loco, observase que os diversos veículos midiáticos contribuem para o processo de encurtamento de distância entra torcedores e times.

Não obstante:

A plasticidade da mercadoria futebol permite que ele seja vendido ou comercializado sob diversas formas: na TV, no telemóvel (novo e promissor mercado), jogos eletrônicos de diversos tipos (inclusive aqueles que simulam a «administração» da parte financeira dos times), revistas especializadas, álbuns de figurinhas, em sites com conteúdo exclusivo (partidas, gols, melhores momentos). (ALVITO, 2006, p. 456)

Isso pode verificado quando os dados da tabela 4, permitem encontrar clubes que fazem parte das principais ligas nacionais do futebol europeu: campeonato inglês, campeonato espanhol, campeonato alemão, campeonato Italiano e campeonato francês ${ }^{15}$. Esses clubes, dentro da sua especificidade, são reconhecidos como clubes globais, pois, de acordo com Rial (2008) tais clubes são futebolisticamente internacionalizados, possuem capital internacional, possuem a "mão-de-obra" centrada em emigrantes (jogadores), aparecem na mídia global e contam com o sentimento de pertencimento de torcedores de diferentes Estados-Nações. Ainda, a autora destaca a importância dos jogadores brasileiros no processo de identificação dos torcedores com clubes do exterior:

A importância dos jogadores brasileiros para os clubes globais pode ser medida, também, numericamente: seu contingente fez do Brasil a segunda nação em números de participantes na Liga dos Campeões em 2004 e a primeira em 2007. Evidentemente, nesse que é o principal campeonato europeu, não há clube brasileiro inscrito. Os futebolistas brasileiros não apenas estão numericamente presentes, mas, mais importante, têm uma presença qualitativamente central pois não raramente ocupam as posições principais em cada equipe, são os destaques, seja atuando no ataque, posições que historicamente

\footnotetext{
${ }^{15}$ Ranking GE: Inglês é a melhor liga da Europa; Francês fica em último no top-5: https://globoesporte.globo.com/futebol/futebol-internacional/noticia/ ranking-ge-ingles-e-a-melhor-liga-da-europa-frances-fica-em-ultimo-notop-5.ghtml.
} 
tem prevalecido como lócus de reconhecimento dos principais jogadores, seja atuando na defesa, o que é uma novidade dos últimos anos pois raramente eram defensores os principais jogadores de uma equipe. (RIAL, 2008, p. 31).

Assim, quando se observa os times de futebol citados, como no caso de Barcelona e Real Madrid, que no decorrer do tempo quase sempre tiveram em seus elencos, jogadores brasileiros (Romário, Ronaldo, Rivaldo, Ronaldinho Gaúcho, Neymar) que foram, em determinado momento, as principais estrelas ou o destaque. Nesse sentido, o elemento jogador pode servir como parâmetro para que o indivíduo possa acompanhar e torcer por determinado time estrangeiro. Também, não se pode negar que a relação de identificação do torcedor com o jogador pode transcender a questão étnica. Isso pode ser verificado em casos como do argentino Lionel Messi e do português Cristiano Ronaldo.

Outro elemento que é possível discutir é a fase dos clubes. Pensou-se nesse aspecto, quando foi visualizado a indicação do Borussia Dortmund ALE. Ressalta-se que tal time fez final da Champions League - principal competição europeia de clubes na temporada 2012/2013 - superando fortes concorrentes como o Real Madrid. No âmbito nacional o Borussia se destaca como o principal adversário do Bayern de Munique (hoje a maior força do futebol alemão). Assim ao que parece, os grandes feitos, as vitórias e conquistas causam efeitos positivos na imagem dos clubes, inclusive atraindo outros torcedores.

Um segmento clubístico que vem chamando atenção, é a ascensão dos clubes denominados como "os novos ricos" da Europa. Esses clubes foram comprados por bilionários, os quais investem em jogadores renomados como é o caso do Manchester City da Inglaterra e Paris Saint-German da França. Este último teve $70 \%$ do clube comprado pela empresa Qatar Sports Investments, a qual tem como CEO e presidente do clube Nasser al-Khelaifi, o qual investiu em vários jogadores de destaque (Ibrahimovic, Cavani, Pastore, Thiago Silva, entre outros.) - batendo de frente com gigantes europeus como Barcelona, Real Madrid e Manchester United. Todo o investimento seja em contratações ou em estrutura para o clube, gera um ganho de capital simbólico e midiático.

Os aspectos supramencionados vêm ganhando cada vez mais espaço no dia-a-dia através da internet, sobretudo com as redes sociais e os games. Em tempos em que as relações virtuais são cada vez mais comuns, têm-se no Facebook, Instagram, Twitter, My Space, Linkedin e outras, um espaço que possibilita a construção de identidades, inclusive a clubística relacionada a clubes europeus. De acordo com Nóbrega:

$\mathrm{Na}$ Era das Novas Tecnologias, as redes sociais firmam seu espaço como importante ferramenta de respaldo na construção das identidades pessoais. Em uma época em que cada vez mais pessoas se utilizam desse tipo de recurso, as redes ganham corpo de intensa influência e revelam-se não como uma tendência passageira, mas como algo que modifica radicalmente as formas de relacionamento na sociedade. (NÓBREGA, 2010, p. 100).

Sobre os games, percebe-se uma diferença considerável de nível entre um time brasileiro e o europeu, direcionando os jogadores a escolherem para jogar times localizados no velho continente. Não obstante, o conjunto de informações sobre os times, jogadores e os diferentes modos do jogo presentes no game, inclusive o modo de jogo online, contribui para que a representação identitária clubística se altere e seja atualizada, sendo esse, um processo dinâmico e contínuo.

\section{CONSIDERAÇÕES FINAIS}

O objetivo deste estudo foi compreender como se dá a construção do gosto pelo time de futebol dos discentes matriculados no Ensino Médio de um Colégio Público Estadual, localizado na região central no município de Ponta Grossa - Paraná, no ano letivo de 2015.

Neste sentido, compreendeu-se que o indivíduo tem como alicerces para a construção do seu gosto a "família", a partir das suas primeiras experiências, com destaque para a figura do "pai". Verificou-se que os times citados, encontram-se localizados nos grandes centros, como nos Estados de São Paulo e Rio de Janeiro. Sobre este aspecto, ressalta-se que o estado do Paraná foi um dos últimos a ter sua formação constituída e dessa forma, é possível pensar que a construção das identidades e, por consequência, dos gostos do "ser paranaense" sofreram influências de diversos povos, sobretudo dos indivíduos que migraram de São Paulo, Rio Grande 
do Sul e estrangeiros. Desta forma, entende-se que o Estado d Paraná, é um local constituído por diversas identidades, as quais se entrelaçam no decorrer da história e do desenvolvimento do mesmo.

Ainda, sobre os times indicados, é possível identificá-los como clubes que compõem o seleto grupo dos "grandes" do futebol brasileiro. Tais clubes possuem um histórico de conquistas de campeonatos nacionais e internacionais, possuem uma cobertura midiática expressiva, possuem torcidas que transcendem seus contextos locais, ou seja, são instituiçoes transnacionais, possuem os maiores valores de patrocínios e cotas de televisão.

Não obstante, identificou-se a existencia de indivíduos com perfis que podem ser categorizados por uma espécie de bifiliação clubística, ou seja, torcem tanto para um time brasileiro, quanto para outro estrangeiro. Observou-se ainda que esta segunda opção, não é determinada pela "família". Verificase desta forma, que esses aspectos são oriundos dos processos de globalização que o esporte, mais especificamente, do futebol, vem atravessando no decorrer dos anos. Por conseguinte, compreende-se que os indivíduos tendem a cada vez mais, através dos diversos veículos midiáticos, sobretudo com a televisão, a internet e seus canais de comunicação, a acompanhar os times e os campeonatos europeus, pois, considera-se que tais times e campeonatos possuem os "melhores jogadores", não só do Brasil, como também do mundo.

\section{REFERÊNCIAS}

ALVITO, M. "A parte que te cabe neste latifúndio": o futebol brasileiro e a globalização. Análise social, Rio de Janeiro, v. 41, n.179. p. 451-474. 2006.

BABBIE, E. Métodos de pesquisa de survey. 2. ed. Belo Horizonte: UFMG, 2003. 519 p.

BARBOSA, A. M. S. O futebol e a sociedade global: uma reavaliação da identidade sociocultural brasileira. Sociedade e cultura. Goiás, v. 10, n. 2, p. 173-186, Jul./Dez. 2007.

BARDIN, L. Análise de conteúdo. Edições 70. São Paulo, 2016. 226 p.

BARRINHA, A.; NUNES, I. O futebol e a globalização. Relações internacionais. Coimbra, n. 02, p. 127-140, jun. 2004.

BAUMAN, Z. Identidade: entrevista a Benedetto Vecchi. Rio de Janeiro: J. Zahar, 2005.
BDO Publicações. $\mathbf{1 0}^{\circ}$ VALOR DAS MARCAS DOS CLUBES BRASILEIROS - FINANÇAS DOS CLUBES. 2017. Disponível em: https://www.bdo.com.br/pt-br/ publicacoes/noticias-em-destaque $/ 10 \% \mathrm{C} 2 \% \mathrm{BA}$-valor-dasmarcas-dos-clubes-brasileiros. Acesso em: 05 de jan 2018.

BERGER, P.; LUCKMANN, T. A construção social da realidade: tratado de sociologia do conhecimento. Petrópolis, RJ: Vozes, 1985.

DA SILVA, S. Identidade no Futebol: O papel do jornalismo esportivo paranaense na formação de uma identidade futebolística regional. 2011, Monografia (Graduação bacharel em Jornalismo). Universidade Positivo, Curitiba, 2011.

DAMO, A. S. Para o que der e vier: o pertencimento clubístico a partir do Grêmio Foot-ball Porto Alegrense e seus torcedores. Dissertação (Mestre em Antropologia social) - Universidade Federal do Rio Grande do Sul, Porto Alegre, 1998.

DAMO, A. S. "Ah! Eu sou gaúcho! O nacional e o regional no futebol brasileiro.". Estudos Históricos. Rio de Janeiro, v.13, n.23, p. 87-117.1999.

DAMO, A. S. Paixão partilhada e participativa - o caso do futebol. História, Questões \& Debates, Curitiba, n. 57, p. 45-72, jul./dez. 2012.

DAÓLIO, J. A. O drama do futebol brasileiro: uma análise socioantropológica. In: DAÓLIO, J. A. (Org). Cultura: educação física e futebol. 3 ed. Campinas: Editora da UNICAMP, 2006, p. 107- 114.

DAOLIO, J. As contradições do futebol brasileiro. EFDeportes, Buenos Aires, v. 3, n. 10, p. 1-1, mai. 1998.

FREITAS JÚNIOR, M. A. Pais, amigos, professores e mídia: influencias externas na definição clubística. In. XIII Encontro Estadual de História - ANPUHPR; 2012, Londrina. Anais [...] Londrina: UEL, 2012. p. 503.

FONSECA, V. L. B. Clubes de futebol: lugares e territórios possíveis. Revista Interface, Palmas, n. 11, p. 183-201. 2016.

GIGLIO, S. S. Futebol: Mitos, ídolos e heróis. Dissertação de Mestrado (Mestre em Educação Física) - Universidade Estadual de Campinas, Campinas, 2007.

GIL, A. C. Métodos e técnicas de pesquisa Social. 6. ed. São Paulo: Atlas S. A., 2008. 200 p

GUEDES, S. L. Subúrbio: celeiro de craque. In: DAMATTA, R. (Org.). Universo do futebol: esporte e sociedade brasileira. Rio de Janeiro: Pinakotheke, 1982. cap. 3, p. 5974.

HELAL, R.; GORDON, C. A crise do futebol brasileiro: perspectivas para o século XXI. Revista Eco-Pós, Rio de Janeiro, n. 1, p. 37-55. 2002. 
KOCH, R.; FORELL, L. Mercadorias pós-modernas: produtividades das migrações de jogadores de futebol na contemporaneidade na constituição dos jovens torcedores. Caderno de Estudos Culturais. Campo Grande, v. 8, n. 15, p. 1-15. 2016.

KOWALSKI, M. Por que Flamengo?. Tese (Doutorado em Educação Física) - Universidade Gama Filho, Rio de Janeiro, 2001.

MAGALHÃES, J. Processos de construção sociais, movimentos autogestionários e consciência crítica. ORG \& DEMO, Marília, v. 5, n. 2, p. 229-246, 2004.

MEZZADRI, F. M. As possíveis interferências do estado na estrutura do futebol brasileiro. In. RIBEIRO, Luiz (Org.). Futebol e Globalização. Ed. 1. Jundiaí: Fontoura, 2007. cap. 5, p.107-128.

MOSKO, J. C. Futebol moderno e a busca pelo capital: o exemplo do Clube Atlético Paranaense. In. Ribeiro, Luiz (Org.). Futebol e Globalização. Ed. 1. Jundiaí: Fontoura, 2007. cap. 4, p. 83-105.

NÓBREGA, L. P. A construção de identidades nas redes sociais. Fragmentos de cultura. Goiânia, v. 20, n. 1, p. 95102, Jan./Fev. 2010.

PRONI, M. W. Esporte-espetáculo e futebol-empresa. Tese (Doutorado em Educação Física) - faculdade de Educação Física, Universidade Estadual de Campinas, Campinas, 1998.

PRONI, M. W; ZAIA, F. H. Gestão empresarial do futebol num mundo globalizado. In. RIBEIRO, Luiz (Org.). Futebol e Globalização. Ed. 1. Jundiaí: Fontoura, 2007. cap. 1, p. 19-47.

RIAL, C. RODAR: a circulação dos jogadores de futebol brasileiros no exterior. Horizontes Antropológicos, Porto Alegre, ano 14, n. 30, p. 21-65, Jul./Dez. 2008.

RIBEIRO, L. C. Brasil: futebol e identidade nacional. EFDeportes, Buenos Aires, Ano. 8, n. 56, p. 1-1. 2003.

RIBEIRO, L. A crise da autonomia no futebol globalizado: a experiência europeia (1985-2007). In. RIBEIRO, Luiz (Org.). Futebol e Globalização. Ed. 1. Jundiaí: Fontoura, 2007. cap 2, p. 49-68.

RODRIGUES, Francisco Xavier Freire. O fim do passe e a modernização conservadora no futebol brasileiro (20012006). Tese (Doutorado em Sociologia) - Universidade Federal do Rio Grande do Sul, Porto Alegre, 2007.

VASCONCELOS, A. A. Identidade futebolística: Os torcedores "mistos no Nordeste". 2011, 90 f. Dissertação de Mestrado [Mestre em Sociologia] - Universidade Federal do Ceará, Ceará, 2011.

VASCONCELOS, A. A. "VERGONHA DO NORDESTE": o discurso dos torcedores "anti-mistos". In. XV ENCONTRO DE CIÊNCIAS SOCIAIS DO NORTE E NORDESTE $\mathrm{e}$
PRÉ-ALAS BRASIL; 2012, Teresina. Resumo [...] Teresina: UFPI, 2012. p.1-15.

VELOZO, E. L.; DAÓLIO, J. Futebol, mundialização e identidades: notas a partir da Eurocopa de 2008. Publicatio, Ponta Grossa, v. 25, n. 2. 2017. p. 257-267. 